\title{
The Role of "Leakage" of Tubular Fluid in Anuria Due to Mercury Poisoning*
}

\author{
Norman Bank, $\dagger$ Bertrand F. Mutz, and Hagop S. Aynedjian \\ (From the Department of Medicine, New York University School of Medicine, \\ New York, N.Y.)
}

\begin{abstract}
Summary. The role of "leakage" of tubular fluid in anuria produced by mercury poisoning was studied in rats by micropuncture techniques. After an initial brisk diuresis, almost all animals were completely anuric 24 hours after $\mathrm{HgCl}_{2}$ injection. Lissamine green injected intravenously in the early stage of anuria appeared in the beginning of the proximal tubule, but the color became progressively lighter as the dye traversed the proximal convolutions. The dye was barely visible in the terminal segments of the proximal tubule; it did not appear at all in the distal tubules. These observations suggest that the proximal epithelium had become abnormally permeable to Lissamine green.

Tubular fluid to plasma inulin $\left(T F / P_{I n}\right)$ ratios and inulin clearance were measured in individual nephrons at three sites: early proximal tubule, late proximal tubule, and distal tubule. It was found that $T F / P_{\text {In }}$ ratios were abnormally low in the late proximal and distal tubules. Inulin clearance was normal at the beginning of the proximal tubule but fell by more than $60 \%$ by the late proximal convolutions. Thus, the proximal tubule had also become permeable to inulin.

We conclude from these observations that anuria in mercury poisoning can occur in the presence of a normal glomerular filtration rate. The absence of urine flow appears to be due to complete absorption of the filtrate through an excessively permeable tubular epithelium. The driving force affecting this fluid absorption is probably the colloid oncotic pressure of the peritubular capillary blood.
\end{abstract}

\section{Introduction}

The pathologic physiology of anuria in acute renal failure remains obscure in spite of extensive study. The three mechanisms that have been postulated are: a severe reduction in renal blood flow and glomerular filtration rate (GFR), obstruction of the tubules by casts or edema, and excessive

* Submitted for publication July 12, 1966; accepted January 4, 1967.

This work was supported by grants from the National Heart Institute (HE-05770), the American Heart Association, and the Life Insurance Medical Research Fund.

† Career Scientist of the Health Research Council of New York City. Address requests for reprints to Dr. Norman Bank, Dept. of Medicine, New York University School of Medicine, 550 First Ave., New York, N. Y. back diffusion of the filtrate through a damaged tubular epithelium. To our knowledge, only three studies have been published in which these various possibilities were examined by direct observation of the kidney in vivo in animals with experimental acute renal failure (1-3). Richards reported that, in the anuric stage of cyanide or mercury poisoning in frogs, flow of fluid from the glomerulus into the beginning of the proximal tubule was normal or even increased (1). The failure of any urine to appear in the ureter was attributed to gross leakage of tubular fluid from more distal segments of the proximal tubule. More recently, Oken and his co-workers, studying acute renal failure due to mercury poisoning (2) and hemoglobinuria (3) in rats, found GFR per nephron 
to be significantly reduced. They concluded that anuria in these two experimental models resulted from intrarenal vasoconstriction and a subsequent fall in filtration rate.

In the present study, we have reinvestigated the role of leakage of tubular fluid in anuria caused by mercury poisoning. The techniques used were rapid sequence photography of the surface tubules after intravenous Lissamine green injection, and quantitative measurements of inulin clearance at various points along the nephron. The findings support the view that the permeability of the tubules is markedly increased and nonselective during the anuric stage of mercury poisoning. Glomerular filtration rate, on the other hand, as evaluated by inulin clearance measured in early segments of the proximal tubule, was within the normal range. We conclude, therefore, that the mechanism of anuria in these animals was excessive back diffusion of the glomerular filtrate through abnormally permeable tubules.

\section{Methods}

Male white rats weighing between 225 and $300 \mathrm{~g}$ were fed a sodium-free diet for 3 or 4 days before the induction of acute renal failure. The reason for eliminating sodium from the diet was to determine whether a reabsorptive defect for sodium occurred during the course of the illness. After 3 or 4 days on the diet, a control urine specimen was collected in a metabolic cage. Tap water was allowed ad libitum during the collection of urine, but food was withheld. Water intake as well as urine output was measured in each animal. Acute renal failure was then induced by subcutaneous injection of $\mathrm{HgCl}_{2}$ solution in a dosage of 3.0 to $3.5 \mathrm{mg}$ per $\mathrm{kg}$ body weight of the mercuric ion. At this dosage, all animals survived at least 48 hours, and $60 \%$ underwent a diuresis and recovered after a period of anuria. During the first 16 hours after $\mathrm{HgCl}_{2}$ injection, a marked diuresis occurred, but beginning at about 20 hours after injection and lasting for an additional 24 to 30 hours, the rats were either totally anuric or severely oliguric. All Lissamine green and micropuncture studies during the anuric stage of the disease were carried out between 24 and 48 hours after $\mathrm{Hg}^{++}$injection. In 22 animals that survived the anuric period, daily urine collections were continued for up to 2 weeks, and in 8 rats of this group, observations on the function of surface tubules were made with the aid of Lissamine green at various intervals during this time. The measurements made on all urine specimens were volume, sodium and potassium concentrations (internal standard flame photometery), and osmolality (Fiske osmometer).

The surgical preparation of the rats was as described previously (4). The left ureter was catheterized with

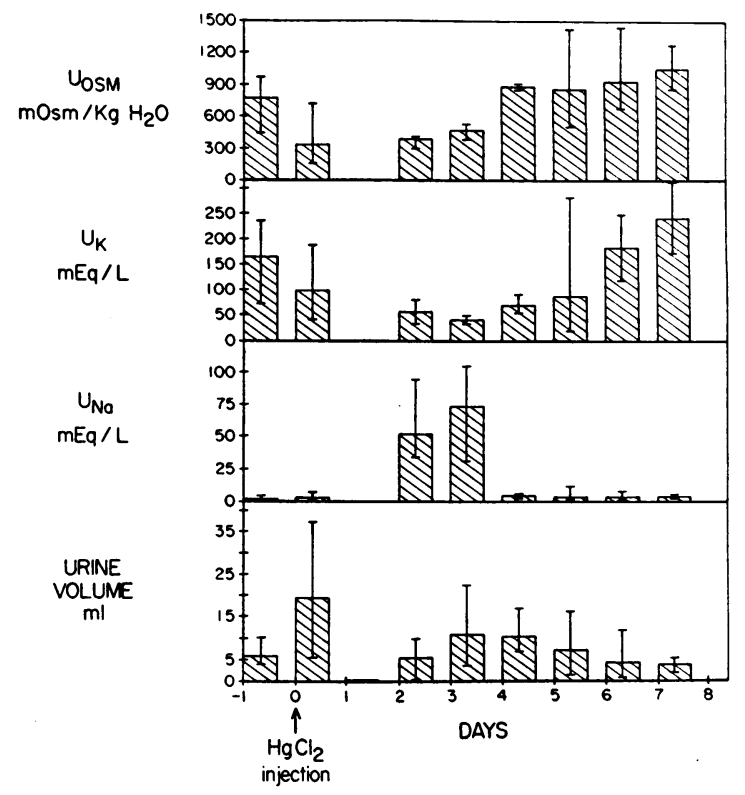

Fig. 1. URINe volume, SODIUM, POTASSIUM, AND osMOLAlity after $\mathrm{HgCl}_{2}$ injection. The rats were fed a sodium-free diet for 3 or 4 days before $\mathrm{HgCl}_{2}$ injection and continued on the diet for the 8 days afterward. The vertical lines indicate the observed range.

polyethylene tubing and the bladder emptied by syringe at the beginning and end of each experiment in order to determine whether there was any urine flow from either kidney. Mean arterial blood pressure was measured in all experiments by a U-tube mercury manometer connected through its sidearm to a catheter secured in the carotid artery. Only those experiments were accepted in which mean blood pressure remained between 100 and $130 \mathrm{~mm} \mathrm{Hg}$. Approximately 4 to $5 \mathrm{ml}$ of isotonic $\mathrm{NaCl}$ was given intravenously during surgical preparation of the rat to replace body fluid losses and to preclude the possibility of salt depletion. A constant infusion of isotonic $\mathrm{NaCl}$ was administered at $0.025 \mathrm{ml}$ per minute throughout the experiment.

Lissamine green experiments. In 15 rats, 24 to 48 hours after $\mathrm{HgCl}_{2}$ administration, the surface of the kidney was photographed sequentially after rapid intravenous injection of 0.04 to $0.07 \mathrm{ml}$ of $10 \%$ Lissamine green, as described by Steinhausen (5). In these animals, the renal capsule was stripped away to improve the clarity of the photographs, and the kidney was bathed in continuously flowing saline warmed to $37^{\circ} \mathrm{C}$. The photographic equipment consisted of a Leitz Ultropak objective and illuminating system, a Zeiss Ukatron electronic flash unit (operated at 60 watt-seconds), and a Leica camera back with a battery-operated motor for automatic film advance. High speed Ektachrome film (ASA 160) was used throughout. Pictures were taken at various intervals after Lissamine green injection, depending upon the appearance of the dye in the structures seen on the surface of the kidney. 

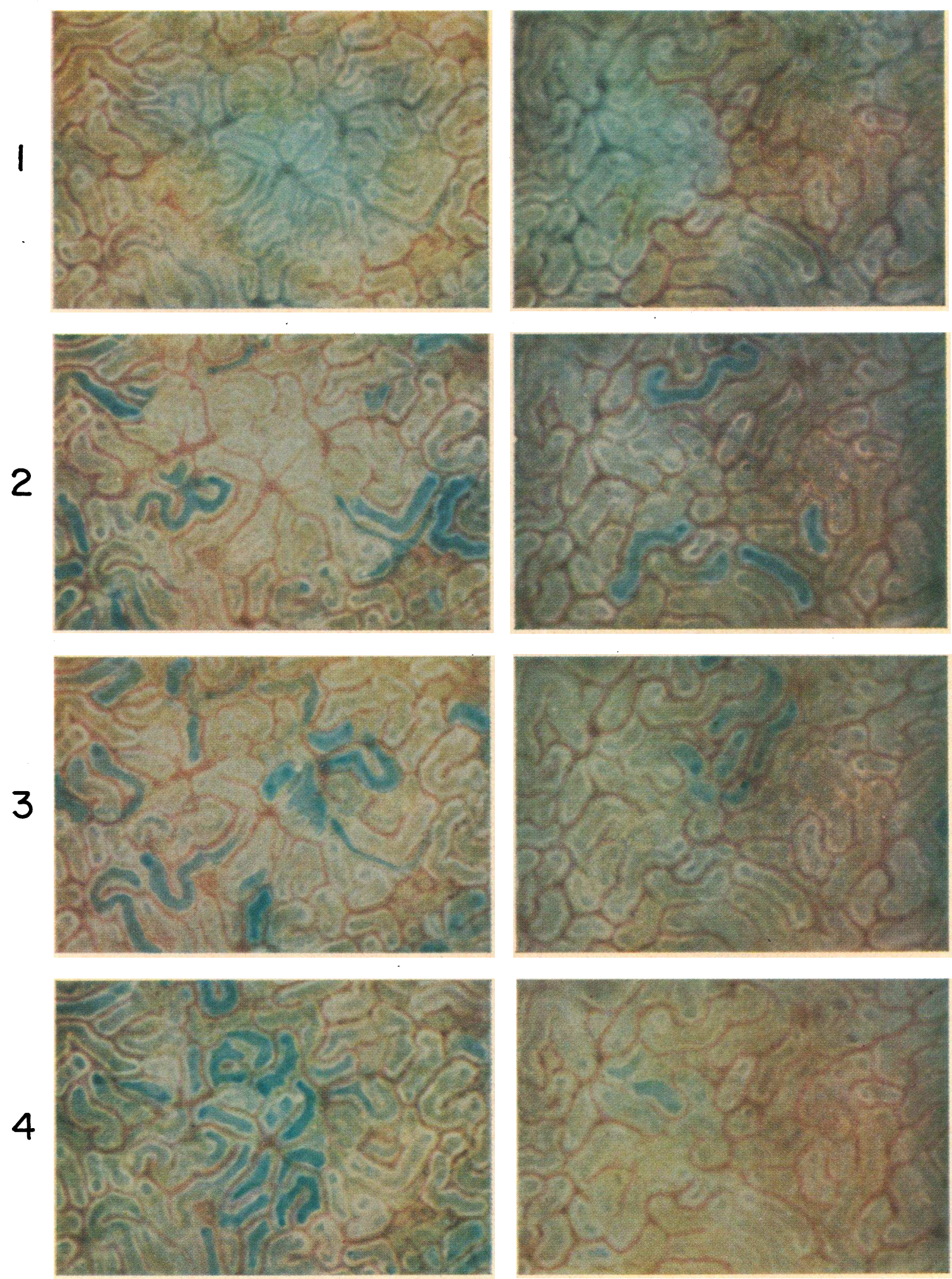

NORMAL

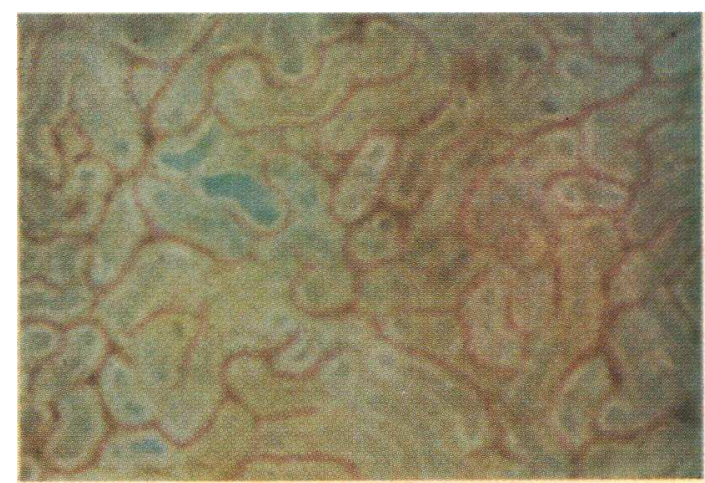

MERCURY

FIG. 2 
Measurement of $T F / P_{\text {In }}$ ratios and inulin clearance per nephron. In eight rats, 24 to 30 hours after $\mathrm{Hg}^{++}$ injection, $\mathrm{TF} / \mathrm{P}_{\text {In }}$ ratios and inulin clearance were measured at various points along the proximal and distal tubules. A priming dose of $25 \mu \mathrm{c}{ }^{14} \mathrm{C}$-labeled inulin carboxylic acid ${ }^{1}$ was given intravenously, and a sustaining dose of $0.4 \mu \mathrm{c}$ per minute in isotonic saline was started 30 minutes before tubular fluid collections were begun. Early proximal segments were identified by injecting Lissamine green intravenously and observing the first intratubular appearance of the dye. Late proximal segments were identified as those clustered about prominent branching capillaries (6), and distal tubules by the thin, glistening appearance of their epithelium. Tubular fluid collections were made from each of these three loci in each animal. A column of heavy castor oil stained with Sudan black was maintained just distal to the collection site to assure that all fluid coming from the glomerulus was aspirated into the pipette. The period of collection was carefully timed with a stopwatch and the volume of the collected fluid measured as described by Windhager and Giebisch (7). The inulin concentration in tubular fluid and plasma was measured by liquid scintillation counting as previously described (8). Plasma inulin concentration at the midpoint of each tubular fluid collection was determined from the plasma inulin curve, blood samples being collected from the cut tail at 30 minute intervals during the experiment. The plasma inulin concentrations were corrected for a plasma water content of $94 \%$. Inulin clearance per nephron was calculated from the expression $\mathrm{TF}$ flow $\times \mathrm{TF} / \mathrm{P}_{\mathrm{In}}$. At the end of each tubular fluid collection, the nephron was injected with colored latex and the site of the collection determined more precisely by microdissection.

In five normal rats also prepared on a sodium-free diet for 3 or 4 days, the potent diuretic furosemide 2 was administered intramuscularly in a dose of $40 \mathrm{mg}$ per $\mathrm{kg}$ body weight. Urine output and water intake were measured for the next 24 hours after which time $T F / P_{\text {In }}$ ratios and inulin clearance along the nephron were measured as described above.

\section{Results}

Urine volume, sodium, potassium, and osmolality (Figure 1). The data obtained from a total of 35 rats followed for various lengths of time up to 8 days after $\mathrm{HgCl}_{2}$ injection are shown in Figure 1. All animals were maintained on a sodium-free diet for 3 or 4 days before $\mathrm{Hg}^{++}$administration and were continued on the diet during the 8 days afterward. During the first 16 hours after $\mathrm{Hg}^{++}$injection, a marked diuresis oc-

\footnotetext{
1 New England Nuclear Corp., Boston, Mass.

2 The furosemide was kindly supplied by Hoechst Pharmaceuticals, Inc., Cincinnati, Ohio.
}

curred, the average urine volume being $18 \mathrm{ml}$. Potassium constituted the major urinary cation during the diuresis, as it did in the control period. Water ingestion paralleled or exceeded urine output during the 16-hour period, the average intake being $25 \mathrm{ml}$. Starting at about 20 to 24 hours, urine flow fell to zero in almost all animals and was greatly reduced in the others. Between 24 and 48 hours after $\mathrm{Hg}^{++}$injection, the animals were virtually anuric, even though water ingestion remained normal in many of them. Urine output resumed in 22 of the 35 animals after this period and exceeded control volumes on the third and fourth days after $\mathrm{Hg}^{++}$. Sodium excretion was markedly increased during the early recovery period in spite of the absence of sodium in the diet. Urinary potassium excretion, on the other hand, was lower than in the control period, as was total urinary osmolality. Between the fourth and seventh days, urinary sodium, osmolality, potassium, and volume all returned to control levels. Although the entire anuric and recovery periods were telescoped as compared with the usual course of acute renal failure in man (9), the pattern of reciprocal changes in urinary sodium and potassium concentrations and the reduction of urinary osmolality are typical of the findings in man (10).

Appearance of the kidney and observations with Lissamine green (Figure 2). At 24 to 28 hours after 3.0 to $3.5 \mathrm{mg}$ per $\mathrm{kg}$ of $\mathrm{Hg}^{++}$was injected subcutaneously, the epithelial lining of the proximal tubules appeared poorly defined, pale, and granular in those segments closest to prominent branching surface blood vessels. These blood vessels, one of which can be seen clearly in the upper left photograph in Figure 2, have been identified as efferent arterioles and the adjacent tubular segments as the most distal portions of the proximal convolutions present on the surface of the kidney (6). Other tubular segments, presumably proximal to the abnormal ones, appeared more normal. When they were examined between 30 and 48 hours after $\mathrm{Hg}^{++}$injection, a more diffuse involvement of the proximal tubules was seen, with almost all segments showing a loss of the usual sharp definition characteristic of the normal proximal epithelium. Proximal tubule lumina could be seen throughout the anuric stage of the disease, but their diameters often could not be judged accurately because of the granularity and 
opacity of the overlying epithelium. In contrast to the normal kidney, only a few patent distal tubules could be recognized in kidneys examined between 24 and 48 hours, but their thinner more glistening epithelium appeared normal.

The appearance of Lissamine green after rapid intravenous injection is illustrated in Figure 2. A sequence of pictures of a normal kidney is shown at the left from top to bottom, and one of a $\mathrm{Hg}^{++}$-poisoned kidney is shown on the right. The latter experiment was carried out 24 hours after $\mathrm{Hg}^{++}$injection. At the time of study, the animal had been totally anuric for 8 hours. Moreover, no urine appeared in either the left ureteral catheter or bladder during the experiment. In both animals, Lissamine green appeared in the surface peritubular capillaries 4 seconds after its intravenous injection. The dye next appeared in the first segment of the proximal tubule 7 seconds after injection. After this point, however, the color intensity decreased progressively in the $\mathrm{Hg}^{++}$ poisoned animal as the dye traversed the proximal convolutions. Toward the end of the proximal tubule, in those segments nearest to the prominent branching arterioles, only a diffuse light green color could be seen. In contrast, in the normal rat, the dye intensity remained essentially unchanged from the beginning to the end of the proximal tubule. The marked difference between the normal and diseased kidneys can be best appreciated by comparing adjacent photographs in Figure 2, which were taken at comparable times after Lissamine green injection. In addition to these observations, we noted that Lissamine green never reappeared in the distal tubules of the anuric animals, as it does in normal rats (5). This was the case even with the few patent distal tubules that were recognized by their characteristic thin epithelium. Similar observations were made in 14 other anuric rats.

$T F / P_{I n}$ ratios and inulin clearance per nephron (Figure 3, Tables $I$ and II). In eight rats studied at 24 to 30 hours after $\mathrm{Hg}^{++}$injection, $\mathrm{TF} / \mathrm{P}_{\text {In }}$ ratios were measured at various points along the nephron, and inulin clearance per nephron was de-

Fig. 2. Appearance OF KIDNEY SURface in vivo DURING PASSAGE OF LISSAMINE GREEN. In both the normal and anuric animals, the pictures were taken at $4,7,15$, and 25 seconds, respectively, after intravenous injection of $10 \%$ Lissamine green. Magnification $110 \times$. termined. In five of the eight, no urine appeared in either the ureteral catheter draining the experimental kidney or in the bladder during the 3 to 4 hours of the experiment. In the other three animals, a volume of urine too small to fill the ureteral catheter was produced by the experimental kidney. The urinary to plasma inulin $\left(\mathrm{U} / \mathrm{P}_{\mathrm{In}}\right)$ ratios in these three animals were $9.56,3.95$, and 1.91 , respectively.

The control group consisted of five normal rats fed a sodium-free diet for 3 or 4 days and given furosemide intramuscularly 24 hours before micropuncture study. Urine output on the day preceding the experiment averaged $26.4 \mathrm{ml}$ and water ingestion, $26.0 \mathrm{ml}$. In contrast to the $\mathrm{Hg}^{++}$-injected animals, urinary sodium concentration rose markedly during the diuretic period to $43 \mathrm{mEq}$ per L. During micropuncture on the following day, each of the five control rats excreted urine at nondiuretic rates, the average flow from the experimental kidney being $8.1 \mu \mathrm{l}$ per minute per $\mathrm{kg}$. The $U / P_{I n}$ ratio in this group averaged 484 .

The $T F / P_{\text {In }}$ ratios are shown in Figure 3 plotted on the ordinate against sites of collection on the abscissa. The ratios were strikingly low in both the proximal and distal tubules of the anuric animals, as compared with the control animals and with normal values reported by numerous investigators $(7,8,11-13)$. The distal $\mathrm{TF} / \mathrm{P}_{\text {In }}$ ratios found in the furosemide-treated rats are somewhat lower than those previously reported for nondiuretic normal rats, perhaps due in part to the

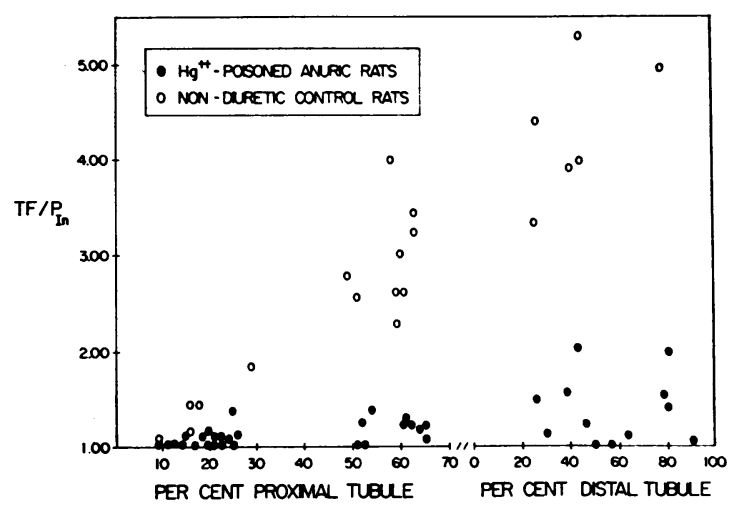

Fig. 3. Tubular fluid to plasma inulin (TF/P $/ \mathrm{P}_{\text {In }}$ ) RATIOS IN ANURIC $\mathrm{Hg}^{++}$-POISONED RATS, AND NONDIURETIC CONTROLs. A striking inability to concentrate inulin is evident in the anuric animals. 
TABLE I

Inulin clearance measured at various points along the nephron in a mercury-poisoned anuric rat*

\begin{tabular}{|c|c|c|c|c|c|}
\hline Time & $\begin{array}{c}\text { TF } \\
\text { sample }\end{array}$ & TF/PIn & $\begin{array}{l}\text { TF flow } \\
\text { rate }\end{array}$ & $\begin{array}{c}\text { Inulin } \\
\text { clearance } \\
\text { per nephron }\end{array}$ & Location \\
\hline minutes & & & $\begin{array}{c}n l / \\
\min / k g\end{array}$ & $\begin{array}{c}n l / \\
m i n / k g\end{array}$ & $\%$ length \\
\hline 0 & \multirow{3}{*}{\multicolumn{5}{|c|}{$\begin{array}{l}\text { Inf usion: } \mathrm{NaCl}, 150 \mathrm{mEq} \text { per } \mathrm{L} \text { at } 0.125 \mathrm{ml} \text { per minute } \\
\text { Inulin-14 } \mathrm{C}, 25 \mu \mathrm{c} \text { intravenously } \\
\text { Infusion: } \mathrm{NaCl}, 150 \text { mEq per } \mathrm{L} \text {; inulin-14 } \mathrm{C}, 17 \mu \mathrm{c} \text { per } \\
\quad \mathrm{ml} \text { at } 0.025 \mathrm{ml} \text { per minute }\end{array}$}} \\
\hline 40 & & & & & \\
\hline 41 & & & & & \\
\hline $92-99$ & 1 & 1.10 & 92 & 101 & $15 \mathrm{P}$ \\
\hline $115-124$ & 2 & 1.54 & 20 & 31 & $78 \mathrm{D}$ \\
\hline $144-151$ & 3 & 1.29 & 40 & 52 & $61 \mathrm{P}$ \\
\hline $170-177$ & 4 & 1.08 & 35 & 38 & $65 \mathrm{P}$ \\
\hline $192-202$ & 5 & 1.39 & 14 & 19 & $80 \mathrm{D}$ \\
\hline $222-237$ & 6 & 0.98 & 10 & 10 & $56 \mathrm{D}$ \\
\hline
\end{tabular}

* Abbreviations: $\mathrm{TF} / \mathrm{PI}_{\mathrm{n}}=$ tubular fluid to plasma inulin ratio; $\mathrm{nl}=$ nanoliters; $\%$ length $=$ per cent of total length of proximal or distal tubule.

large sodium diuresis on the preceding day and a subsequent decrease in medullary hypertonicity.

In addition to $\mathrm{TF} / \mathrm{P}_{\mathrm{In}}$ ratios, tubular fluid flow rates were measured in these experiments, and inulin clearance per nephron was calculated for var-
TABLE II

Inulin clearance measured at various points along the nephron*

\begin{tabular}{|c|c|c|c|}
\hline & $\underset{\text { proximal }}{\text { Early }}$ & $\begin{array}{c}\text { Late } \\
\text { proximal }\end{array}$ & Distal \\
\hline $\begin{array}{l}\mathrm{Hg}^{++} \\
\text {rats }\end{array}$ & $\begin{array}{c}\mathrm{nl} / \mathrm{min} / \mathrm{kg} \\
110 \pm 26 \dagger\end{array}$ & $\begin{array}{c}n l / \min / k g \\
40.5 \pm 26.2 \\
\mathrm{p}<0.001 \ddagger\end{array}$ & $\begin{array}{c}n l / m i n / k g \\
28.6 \pm 20.6\end{array}$ \\
\hline $\begin{array}{c}\text { Control } \\
\text { rats }\end{array}$ & $103 \pm 21$ & $\begin{array}{l}88.9 \pm 26.0 \\
0.1<p<0.2\end{array}$ & $\begin{array}{l}91.2 \pm 20.8 \\
0.2<\mathrm{p}<0.3\end{array}$ \\
\hline
\end{tabular}

* Inulin clearance per nephron was calculated from the expression TF flow $X$ TF $/$ PIn.

+ Data expressed as mean \pm standard deviation.

$\ddagger$ p values compare late proximal or distal tubular inulin clearance with early proximal tubular inulin clearance.

ious collection sites. A typical experiment on an anuric rat is shown in detail in Table I, and the data from all eight anuric and five control animals are summarized in Table II. Inulin clearance measured in early proximal segments was not significantly different from that measured in the control animals or that previously reported from this laboratory in which random collections from

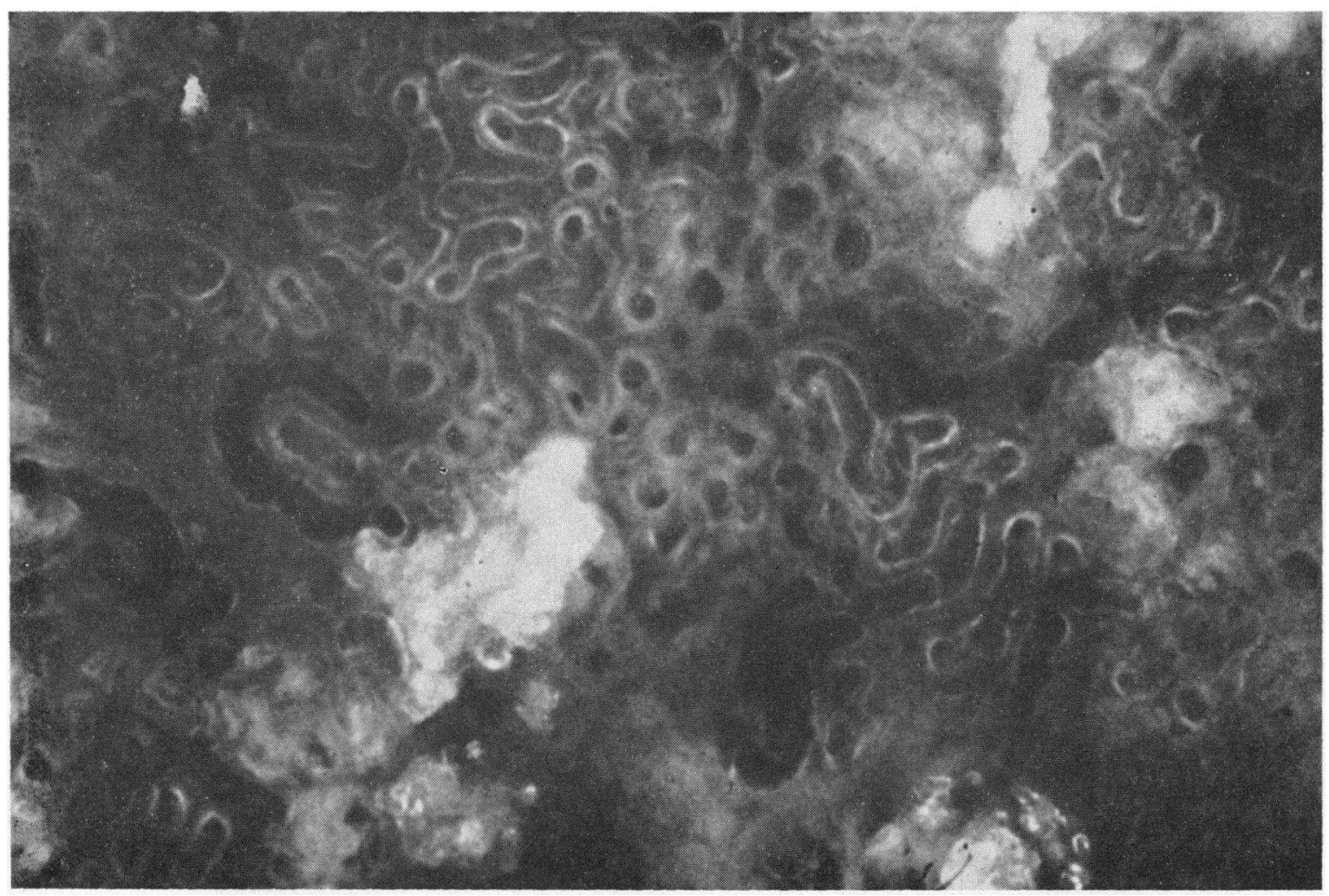

Fig. 4. Appearance of kidney surface in vivo after Clinical ReCOVERy from $\mathrm{HgCl}_{2}$-INdUCEd aCUTE RENAL FAILURE. Intraluminal cellular debris obstructs many tubule segments. The internal diameter of the functioning tubules is $25 \%$ larger than normal. Magnification $65 \times$. 
the proximal tubule had been made (11). When measured in the late proximal segments, however, inulin clearance averaged only $37 \%$ of the early proximal values and in the distal tubule fell to $26 \%$. In the control rats, the site of tubular fluid collection had no apparent influence upon calculated inulin clearance per nephron.

Recovery stage (Figure 4). In eight rats that had recovered from acute renal failure, Lissamine green photographic studies were carried out at periods ranging from 5 to 17 days after $\mathrm{Hg}^{++}$injection. Urinary sodium, potassium, and osmolality had all returned to control levels by this time. In spite of the apparently normal urine, however, examination of the surface of the kidney revealed numerous tubules that contained what appeared to be cellular debris. Lissamine green did not pass through these segments, and we assumed that such nephrons were partially or completely blocked. Adjacent tubules through which Lissamine green did flow were significantly dilated. A typical example of the appearance of the surface of the kidney 17 days after $\mathrm{Hg}^{++}$injection is shown in Figure 4. The heterogeneity of the nephron population is clearly evident. The average luminal diameter of the functioning tubules in this field was $29.5 \mu$, as compared with an average of 23.5 in the normal rats. These observations suggest that tubular obstruction, which can occur during the anuric stage of mercury poisoning (2), may persist for some time after the diuresis and could possibly account for certain functional abnormalities found long after clinical recovery from an episode of acute renal failure $(14,15)$.

\section{Discussion}

Several observations indicate that the $\mathrm{Hg}^{++}-\mathrm{in}$ jected rats were in a true state of acute renal failure when Lissamine green and micropuncture studies were carried out. First, after an initial diuresis induced by the $\mathrm{HgCl}_{2}$ injection, no urine was excreted for periods ranging from 4 to 24 hours before study, in spite of the fact that water intake remained normal in most animals. Furthermore, during the acute studies where one ureter was catheterized and the bladder emptied by syringe, little or no urine appeared from either kidney, even though 4 to $5 \mathrm{ml}$ of saline had been administered during the surgical preparation of the animal. It seems unlikely that the absence of urine flow was due to dehydration secondary to the large diuresis on the preceding day, since water intake during the diuretic period exceeded urine output. To exclude this possibility more rigorously, however, we injected normal sodium-deprived control rats with furosemide, which induced a significantly greater diuresis than did the $\mathrm{HgCl}_{2}$ and, moreover, resulted in considerable loss of sodium in the urine. ${ }^{3}$ In contrast to the $\mathrm{Hg}^{++}$ poisoned animals, all furosemide-treated rats excreted quantities of urine during the acute experiments that were easily measurable. Thus, the absence of urine flow in the $\mathrm{Hg}^{++}$-injected rats cannot be attributed to dehydration. Finally, in three of the $\mathrm{Hg}^{++}$-poisoned animals in which a small amount of urine did appear in the ureteral catheter, $\mathrm{U} / \mathrm{P}_{\text {In }}$ ratios averaged only 5.14. In the control rats with larger urine flows, $U / \mathrm{P}_{\mathrm{In}}$ ratios averaged 484 . These observations are compatible with a diagnosis of acute renal failure in the $\mathrm{HgCl}_{2}$-injected rats.

In the experiments with Lissamine green in the anuric animals, the dye appeared in the capillaries on the surface of the kidney and in the beginning of the proximal tubule in what was judged to be a normal amount and time after its intravenous injection. However, as the dye progressed along the proximal convolutions, its concentration appeared to decrease markedly so that in most cases only a pale diffuse coloration was visible in the terminal segments on the surface of the kidney. Moreover, no dye was ever seen to reappear in the distal tubules as it does in normal rats, where, in the nondiuretic state, it is seen in its most concentrated form (5). It seems likely that these observations were due to an increase in the permeability of the tubules to Lissamine green rather than to some alteration in the hydrodynamics of tubular fluid flow. Although it is theoretically possible that an abnormally slow moving column of tubular fluid might allow longitudinal diffusion of Lissamine green and therefore dilution of the dye,

\footnotetext{
3 The fact that the $\mathrm{HgCl}_{2}$-induced diuresis was accompanied by a large increase in $\mathrm{K}^{+}$excretion but not in $\mathrm{Na}^{+}$ excretion could be explained by a proximal site of action of the compound. Inhibition of proximal $\mathrm{Na}^{+}$reabsorption could result in a large distal $\mathrm{Na}-\mathrm{K}$ exchange, especially since the rats were salt-deprived. Furosemide, on the other hand, has been shown to act principally on the ascending limb of the loop of Henle (16), and thus increased $\mathrm{Na}^{+}$excretion in spite of salt deprivation.
} 
this has not been observed during acute reductions in GFR produced by controlled hemorrhage (17, 18 ), constriction of the abdominal aorta (13), or increased ureteral pressure (13). With very severe reductions in filtration rate and slowing of tubular fluid flow produced by hematin injection, color intensity is increased in the proximal tubule, and the dye is almost black when it reaches the distal tubule (19). Finally, the rate of tubular fluid flow in early segments of the proximal tubule was within normal limits in the $\mathrm{Hg}^{++}$-poisoned rats, as indicated by the inulin clearance measurements in Table II. Thus, the loss of Lissamine green color observed in these experiments cannot be accounted for by a reduction in filtration rate or in tubular fluid flow. Although retention of water in the tubular lumen as occurs, for example, in partially or completely obstructed nephrons might lead to dilution of the dye, this explanation seems unlikely, since the proximal tubules were not obviously dilated and it has been demonstrated that intraluminal pressure is not elevated in $\mathrm{Hg}^{++}$-produced anuria (2). The observations are most compatible, therefore, with the view that the tubules had become excessively permeable to Lissamine green. Since there was a concentration gradient of the dye between tubular lumen and peritubular capillary blood (the vascular phase of dye passage is over before the tubular phase begins, as seen in Figure 2), dye might have been lost by diffusion down a concentration gradient. The site of increased permeability appeared to be the more distal segments of the proximal convoluted tubule in the earliest stage of the disease studied, but deeper segments such as the pars recta and loops of Henle may also have been involved. Our observations are in agreement with those of Richards (1), who described leakage of phenolsulphonphthalein from the proximal tubules of both excised and in situ frog kidneys that had been poisoned with $\mathrm{HgCl}_{2}$.

Further evidence of loss of selective permeability of the tubules was found in the micropuncture experiments. Measurement of $\mathrm{TF} / \mathrm{P}_{\text {In }}$ ratios along the proximal and distal convoluted tubules showed a striking inability to concentrate inulin. The highest ratio found in the proximal tubule was only 1.40 and that in the distal tubule, 2.08, and many measurements were not significantly higher than 1.0. These values differ markedly from those measured in the proximal and distal tubules of the nondiuretic control animals. That these low $\mathrm{TF} / \mathrm{P}_{\mathrm{In}}$ ratios were not due to retention of water in the lumen but rather to leakage of inulin out of the lumen is indicated by the inulin clearance per nephron measurements summarized in Table II. In the control animals, inulin clearance was essentially uniform when measured at various sites along the nephron. In the experimental animals, however, an average fall in inulin clearance of $63 \%$ was found when samples were collected from the late proximal tubule, and a further fall was observed in the distal tubule. The average value for distal tubular inulin clearance may be misleadingly high, however, as it represents collections from what appeared to be a reduced number of patent distal tubules. An apparent reduction in the number of recognizable distal tubules could be the result of complete absorption of the glomerular filtrate more proximally in many of the nephrons, with subsequent collapse of the distal lumina. In any case, the data indicate that much of the filtered inulin had left the lumen along the length of the proximal tubule, and that even more was lost before fluid reached the distal convolution. These observations thus provide a physiological counterpart for histological and histochemical studies that have shown the major site of injury in mercury poisoning to be the more distal segments of the proximal convoluted tubule and the pars recta (20-22).

From the data in Table II, it should be noted that inulin clearance measured in the early proximal tubule was essentially the same in the anuric animals as in the control rats; both values agree closely with those previously reported for normal rats (11). Thus, glomerular filtration rate was apparently within the normal range in the totally anuric animals. This observation also agrees with that of Richards, who noted a brisk flow of fluid from the glomerulus into the beginning of the proximal tubule in anuric mercury-poisoned frogs (1). Since our data demonstrated a major disruption of tubular permeability, we assumed that anuria in these animals was due to complete absorption of a normally formed glomerular filtrate along the length of the nephron. The site of final absorption of the filtrate and collapse of the lumen was presumably distal to the surface proximal convolutions, since in the early stages of 
total anuria fluid could still be aspirated from the most distal portions of the proximal tubule on the surface of the kidney.

The mechanism of complete absorption of the glomerular filtrate through an abnormally permeable epithelium is not entirely clear. Since mercury poisoning probably inhibits active sodium transport (23), some other driving force must have been responsible for passive movement of water across the epithelium. The only other force of sufficient magnitude to accomplish this is the colloidal oncotic pressure of the peritubular capillary blood, which is equivalent to approximately $35 \mathrm{~cm}$ of water (2). Normally, colloidal oncotic pressure plays little or no role in influencing water absorption (24), presumably because of the permeability characteristics of the interposed cell membranes. In mercury nephrotoxicity, however, membrane permeability might increase to the point where this considerable force can be exerted more directly on the fluid in the tubular lumen.

The observations made in this study differ in several respects from those reported by Flanigan and Oken (2), who also studied mercury poisoning in rats by micropuncture techniques. These authors found a reduction in individual nephron filtration rates averaging 55\% when measured at 6 hours after a dose of $\mathrm{HgCl}_{2}$ approximately three times larger than we used. $\mathrm{TF} / \mathrm{P}_{\mathrm{In}}$ ratios in their animals rose progressively along the length of the proximal tubule and were indistinguishable from those measured in normal rats. The reason for these differences between their study and ours is not entirely clear, but they could be explained by a dual effect of $\mathrm{Hg}^{++}$on the kidney at different dose levels and by the time after $\mathrm{Hg}^{++}$injection when micropuncture experiments were carried out. It has been found that a variety of mercury compounds cause a sharp reduction in renal blood flow and glomerular filtration rate shortly after their intravenous injection $(25,26)$. This effect, which is thought to be due to renal vasoconstriction, is transitory unless the dose is high enough to cause a fall in blood pressure. In this case, the reduction in renal blood flow and GFR lasts for several hours and may prevent the expected diuresis (25). That such a response may have occurred shortly after $\mathrm{Hg}^{++}$injection in the rats studied by Flanigan and Oken is suggested by the fact that their animals had little or no initial diuresis. Instead, urine flow fell to oliguric levels soon after drug administration. Furthermore, since they injected the $\mathrm{Hg}^{++}$ intramuscularly, it seems reasonable that renal vasoconstriction might have persisted for longer periods than after intravenous injection. The reduction in single nephron GFR that they found at 6 hours might have been due, therefore, to a prolonged effect on the renal blood vessels. The toxic effect on the tubules that we observed at 24 to 48 hours after $\mathrm{Hg}^{++}$injection had apparently not yet become manifest at 6 hours." Because our animals responded to a smaller dose of $\mathrm{Hg}^{++}$with a large diuresis, we assumed that renal blood flow and GFR were not severely reduced during the first hours after the injection. From this interpretation of the two studies, we conclude that, in high dosages, $\mathrm{HgCl}_{2}$ may produce oliguria or even anuria by causing a reduction in blood flow and GFR. This effect should be transient $(25,26)$, however, and should not in itself produce the abnormalities in urinary electrolyte composition seen in patients with acute renal failure (10) and in our rats. The more prolonged anuria produced by $\mathrm{Hg}^{++}$poisoning, which can occur in the presence of a normal filtration rate, appears to be due to a toxic effect on the tubules leading to increased permeability and complete absorption of the glomerular filtrate.

\section{References}

1. Richards, A. N. Direct observations of change in function of the renal tubule caused by certain poisons. Trans. Ass. Amer. Phycns 1929, 44, 64.

2. Flanigan, W. J., and D. E. Oken. Renal micropuncture study of the development of anuria in the rat with mercury-induced acute renal failure. J. clin. Invest. 1965, 44, 449.

3. Oken, D. E., M. L. Arce, and D. R. Wilson. Glycerol-induced hemoglobinuric acute renal failure in the rat. I. Micropuncture study of the development of oliguria. J. clin. Invest. 1966, 45, 724.

4. Bank, N. Relationship between electrical and hydrogen ion gradients across rat proximal tubule. Amer. J. Physiol. 1962, 203, 577.

5. Steinhausen, M. Eine Methode zur Differenzierung proximaler und distaler Tubuli der Nierenrinde von Ratten in vivo und ihre Anwendung zur

4 The possibility that a reduction in renal blood flow produced by large doses of $\mathrm{Hg}^{++}$may actually afford some protection to the tubules is suggested by the fact that only $33 \%$ of Flanigan and Oken's rats became totally anuric in 24 hours. With smaller doses of $\mathrm{Hg}^{++}$, almost all of the rats in this study were anuric at 24 hours. 
Bestimmung tubulärer Strömungsgeschwindigkeiten. Pflügers Arch. ges. Physiol. 1963, 277, 23.

6. Gertz, K. H., J. A. Mangos, C. Braun, and H. D. Pagel. On the glomerular tubular balance in the rat kidney. Pflügers Arch. ges. Physiol. 1965, 285, 360 .

7. Windhager, E. E., and G. Giebisch. Micropuncture study of renal tubular transfer of sodium chloride in the rat. Amer. J. Physiol. 1961, 200, 581.

8. Bank, N., and H. S. Aynedjian. A micropuncture study of renal bicarbonate and chloride reabsorption in hypokalaemic alkalosis. Clin. Sci. 1965, 29, 159.

9. Swann, R. C., and J. P. Merrill. The clinical course of acute renal failure. Medicine (Baltimore) 1953, 32, 215.

10. Meroney, W. H., and M. E. Rubini. Kidney function during acute tubular necrosis: clinical studies and a theory. Metabolism 1959, 8, 1.

11. Glabman, S., H. S. Aynedjian, and N. Bank. Micropuncture study of the effect of acute reductions in glomerular filtration rate on sodium and water reabsorption by the proximal tubules of the rat. J. clin. Invest. 1965, 44, 1410.

12. Gottschalk, C. W. Renal tubular function: lessons from micropuncture. Harvey Lect. 1963, series $58,99$.

13. Rector, F. C., Jr., F. P. Brunner, and D. W. Seldin. Mechanism of glomerulotubular balance. I. Effect of aortic constriction and elevated ureteropelvic pressure on glomerular filtration rate, fractional reabsorption, transit time, and tubular size in the proximal tubule of the rat. J. clin. Invest. 1966, 45, 590.

14. Finkenstaedt, J. T., and J. P. Merrill. Renal function after recovery from acute renal failure. New Engl. J. Med. 1956, 254, 1023.

15. Price, J. D. E., and R. A. Palmer. A functional and morphological follow-up study of acute renal failure. Arch. intern. Med. 1960, 105, 90.
16. Suki, W., F. C. Rector, Jr., and D. W. Seldin. The site of action of furosemide and other sulfonamide diuretics in the dog. J. clin. Invest. 1965, 44, 1458.

17. Steinhausen, M., A. Loreth, and S. Olson. Messungen des tubulären Harnstromes, seine Beziehungen zum Blutdruck und zur Inulin-Clearance. Pflügers Arch. ges. Physiol. 1965, 286, 118.

18. Steinhausen, M. Personal communication.

19. Gessler, U., and K. Schroder. Experimental studies on the GFR during acute anuria. Presented at the Third International Congress of Nephrology, Washington, 1966.

20. Rodin, A. E., and C. N. Crowson. Mercury nephrotoxicity in the rat. I. Factors influencing the localization of the tubular lesions. Amer. J. Path. 1962, 41, 297.

21. Rodin, A. E., and C. N. Crowson. Mercury nephrotoxicity in the rat. II. Investigation of the intracellular site of mercury nephrotoxicity by correlated serial time histologic and histoenzymatic studies. Amer. J. Path. 1962, 41, 485.

22. Taylor, N. S. Histochemical studies of nephrotoxicity with sublethal doses of mercury in rats. Amer. J. Path. 1965, 46, 1.

23. Kleinzeller, A., and J. H. Cort. The mechanism of action of mercurial preparations on transport processes and the role of thiol groups in the cell membrane of renal tubuler cells. Biochem. J. 1957, 67, 15.

24. Giebisch, G., R. M. Klose, G. Malnic, W. J. Sullivan, and E. E. Windhager. Sodium movement across single perfused proximal tubules of rat kidneys. J. gen. Physiol. 1964, 47, 1175.

25. Farah, A. Renal vascular changes produced by the mercurial diuretic salyrgan. Naunyn-Schmiedeberg's Arch. exp. Path. Pharmak. 1952, 215, 29.

26. Vargas, R., and E. J. Cafruny. Effects of mercurial compounds on renal perfusion pressure. J. Pharmacol. exp. Ther. 1962, 135, 112. 